\title{
Shakespearean Style and Technique in Modern Assamese Drama: A Study of Reception and Response
}

\author{
Mohammad Rezaul Karim \\ Department of Management \\ College of Business Administration \\ Prince Sattam bin Abdulaziz University \\ Al Kharj, Saudi Arabia
}

\begin{abstract}
William Shakespeare's influence extends from theatre and literature to present-day movies and the English language itself. Widely regarded as the most excellent writer of the English language, and the world's preeminent dramatist, Shakespeare transformed the world literature. He was the main generative force behind the entire Indian dramatic literature in various languages including modern Assamese dramas. This influence of Shakespeare helped develop a new kind of drama that is unknown to Assamese dramatic literature. His technique, characterization, and style were borrowed, resulting in an emergence of a new type of drama in the Assamese literature. The Assamese dramas of the pre-independence period owe for its rapid growth to its contact with the West in general and Shakespeare in particular. The researcher in this paper aims to dive deep into the Assamese dramas and dig out the receptions and responses to Shakespeare by the Assamese playwrights concerning his style, technique, and characterization. The researcher, keeping in mind the voluminous of the area, has limited his research area and selected the dramas of the preindependence period for the study of reception and response to William Shakespeare. With the aid of the comparative method of investigation, the researcher finds that influences formerly Western and mainly Shakespearean played a cardinal role in the development of modern Assamese drama. Keywords: Shakespeare, Assamese drama, influence, characterization, style, technique
\end{abstract}

Cites as: Karim, M. R. (2019). Shakespearean Style and Technique in Modern Assamese Drama: A Study of Reception and Response. Arab World English Journal for Translation \& Literary Studies3 (4) 107-117. DOI: http://dx.doi.org/10.24093/awejtls/vol3no4.9 